\title{
Clinical outcome of surgical management for symptomatic metastatic spinal cord compression from prostate cancer
}

\author{
Yasuhide Miyoshi $^{1 *} \mathbb{D}$, Takashi Kawahara', Masahiro Yao ${ }^{1}$ and Hiroji Uemura ${ }^{1}$
}

\begin{abstract}
Background: Metastatic spinal cord compression (MSCC) from prostate cancer (PC) influences not only patients' prognosis but also their quality of life. However, little is known about the clinical outcome of surgery for MSCC from PC. We evaluated both the oncological and functional outcomes of decompression and reconstruction surgery for patients with symptomatic MSCC from PC.

Methods: We assessed 19 patients who underwent decompression and reconstruction surgery for symptomatic MSCC from PC. Of these 19 patients, 8 had metastatic hormone-naïve PC (mHNPC) and 11 had metastatic castration-resistant PC (mCRPC).

Results: The median age of the patients with mHNPC and MCRPC was 72 and 65 years, respectively. The median prostate-specific antigen level at the time of diagnosis of MSCC in patients with mHNPC and MCRPC was 910 and $67 \mathrm{ng} / \mathrm{mL}$, respectively. Although two of eight patients (25.0\%) with $\mathrm{mHNPC}$ were ambulatory preoperatively, six patients (75.0\%) were ambulatory postoperatively. Among 11 patients with $\mathrm{mCRPC}$, only 3 (27.3\%) were ambulatory preoperatively, while $6(54.5 \%)$ were ambulatory postoperatively. The median postoperative overall survival among patients with $\mathrm{mHNPC}$ and $\mathrm{mCRPC}$ were not reached and 8 months, respectively.

Conclusions: Decompression and reconstruction surgery for symptomatic MSCC from PC might contribute to a favorable functional outcome among men with mHNPC and mCRPC. However, its role in improving the oncological outcome remains unclear. The treatment strategy should be chosen by shared decision-making among patients, urologists, radiation oncologists, and orthopedic surgeons.
\end{abstract}

Keywords: Prostate cancer, Castration-resistant prostate cancer, Spinal cord compression, Bone metastas

\section{Background}

The incidence of prostate cancer (PC) has increased worldwide [1]. Although prostate-specific antigen screening has contributed to improvement in PC-related mortality [2], PC remains a leading cause of mortality and morbidity worldwide [1]. Metastatic hormone-naïve PC (mHNPC) is androgen-dependent, and androgen ablation

\footnotetext{
* Correspondence: miyoyasu@med.yokohama-cu.ac.jp

'Department of Urology and Renal Transplantation, Yokohama City University Medical Center, 4-57 Urafune-cho, Minami-ku, Yokohama, Kanagawa 2320024, Japan

Full list of author information is available at the end of the article
}

therapy is initially effective; however, most patients with mHNPC become resistant to androgen ablation therapy and failed to metastatic castration-resistant PC (mCRPC) [3]. Osseous metastases are common in both patients with mHNPC and mCRPC $[4,5]$ and impair patients' quality of life because of skeletal-related events. Approximately onethird of PC metastases to the spine become symptomatic, resulting in metastatic spinal cord compression (MSCC) [6] or mechanical instability [7] .

MSCC occurs in 5\% of patients who die of cancer [8] and contributes to an unfavorable prognosis and poor

(c) The Author(s). 2020 Open Access This article is licensed under a Creative Commons Attribution 4.0 International License, which permits use, sharing, adaptation, distribution and reproduction in any medium or format, as long as you give appropriate credit to the original author(s) and the source, provide a link to the Creative Commons licence, and indicate if changes were made. The images or other third party material in this article are included in the article's Creative Commons licence, unless indicated otherwise in a credit line to the material. If material is not included in the article's Creative Commons licence and your intended use is not permitted by statutory regulation or exceeds the permitted use, you will need to obtain permission directly from the copyright holder. To view a copy of this licence, visit http://creativecommons.org/licenses/by/4.0/. The Creative Commons Public Domain Dedication waiver (http://creativecommons.org/publicdomain/zero/1.0/) applies to the data made available in this article, unless otherwise stated in a credit line to the data. 
quality of life. MSCC can cause irreversible neurological impairment and a short survival time; therefore, an effective treatment strategy for MSCC is important to not only prolong the survival time but also improve the quality of life among men with mHNPC and mCRPC [9].

Decompression surgery is the standard of care for symptomatic MSCC from various cancers, including PC [10]. However, the clinical outcome of surgery for MSCC from PC has not been fully described because of the limited number of patients. In this study, we evaluated the oncological and functional outcomes of decompression and reconstruction surgery for MSCC from PC.

\section{Methods}

\section{Patients}

We retrospectively assessed 19 patients who underwent decompression and reconstruction surgery for symptomatic MSCC from PC from 2002 to 2017 in Yokohama City University Medical Center and Yokohama City University Hospital. The indication for surgery was determined by multidisciplinary team management (shared decision-making among the patients, urologists, orthopedic surgeons, and radiation oncologist) under consideration of each patient's prognosis, neurological deficits, and overall health status. In general, patients with $a<1$ year prognosis and fixed neurological deficits were not recommended for surgery. The metastatic site and spinal cord compression were evaluated by computed tomography and magnetic resonance imaging. Before surgery for MSCC, all patients received high-dose dexamethasone as the initial treatment to prevent irreversible neurological impairment. Of the 19 patients included in the study, 8 had mHNPC and 11 had mCRPC. All patients had pathologically confirmed prostate adenocarcinoma. Clinical data were collected from each patient's medical records. Tumor grades were classified by the Gleason grading system according to the 2014 International Society of Urological Pathology consensus [11].

The extent of disease on the initial bone scan [12] was used for objective semi-quantitative classification of the osseous metastases: $0=$ normal or abnormal because of benign bone disease; 1 = fewer than 6 bony metastases, each of which is less than $50 \%$ of the size of a vertebral body ( 1 lesion about the size of a vertebral body was counted as 2 lesions); $2=6$ to 20 bone metastases, sized as described above; $3=$ more than 20 metastases but fewer than the number of metastases seen in a "superscan"; and 4= "superscan" or its equivalent (i.e., more than $75 \%$ of the ribs, vertebrae, and pelvic bones). The surgical sites for MSCC were classified into five sites: the cervical spine, cervical-thoracic spine, thoracic spine, thoracic-lumbar spine, and lumbar spine.

\section{Surgical procedures and postoperative radiation therapies for MSCC}

The standard surgical procedures were posterior decompression and stabilization. Patients without mechanical instability and with preservation of sagittal alignment of the spine were treated by decompression alone, although the surgical procedures performed were at each surgeon's discretion. An early rehabilitation program specific to the patient's spinal cord injury was implemented. Postoperative radiation was not used in patients with mHNPC because primary androgen deprivation therapy was expected to be effective. In contrast, postoperative radiation was recommended for patients with $\mathrm{mCRPC}$ if the patient could tolerate radiation therapy.

\section{Medical treatments for PC}

The standard medical therapy for mHNPC was androgen deprivation therapy. No patients received cytotoxic agents or new androgen receptor-targeted therapy (abiraterone and/or enzalutamide) for mHNPC. After failed to CRPC, bisphosphonates or denosumab, new androgen receptor-targeted therapy, radium-223, or cytotoxic agents (docetaxel with steroids and/or cabazitaxel with steroids) were used if these agents were approved in Japan when the physician decided to use them. The treatment sequence for mCRPC was at the physician's discretion.

\section{Evaluation of functional outcome}

The Frankel grading classification [13] was used for the functional evaluation preoperatively and 3 months postoperatively. The Frankel grading classification reveals the extent of the neurological/functional deficit caused by spinal cord injury and was established by Frankel et al. [13] in 1969. This classification system is divided into five grades: (A) no function, (B) sensory only, (C) some sensory and motor preservation, (D) useful motor function, and (E) normal. Frankel grades D and E indicate an ambulatory state.

\section{Evaluation of oncological outcome}

The Kaplan-Meier product-limit method was used to estimate the overall survival (OS) distribution after surgery for MSCC. All analyses were conducted using IBM SPSS Statistics software for Windows, version 24 (IBM Corp., Armonk, NY, USA).

\section{Ethics}

The experimental procedures were conducted in accordance with the ethical standards of the Helsinki Declaration. 


\section{Results}

\section{Patients' characteristics}

Table 1 shows the patients' characteristics. The median age of the patients with $\mathrm{mHNPC}$ and $\mathrm{mCRPC}$ at the time of surgery for MSCC was 72 and 65 years, respectively. The median prostate-specific antigen concentration at the diagnosis of MSCC in patients with $\mathrm{mHNPC}$ and $\mathrm{mCRPC}$ was 910 and $67 \mathrm{ng} / \mathrm{mL}$, respectively. The sites of decompression surgery in patients with $\mathrm{mHNPC}$ were the thoracic spine in six $(75.0 \%)$ patients and the lumbar spine in two (25.0\%), and those in patients with mCRPC were the cervical spine in one $(9.1 \%)$ patient, the cervical-thoracic spine in two (18.2\%), the thoracic spine in six (54.5\%), the thoracic-lumbar spine in one (9.1\%), and the lumbar spine in one $(9.1 \%)$. The median time to decompression surgery from symptom onset was 4 days in patients with $\mathrm{mHNPC}$ and 2 days in patients with mCRPC. Bone-targeted agents such as zoledronic acid and denosumab were used in four (36.3\%) patients with $\mathrm{mCRPC}$ and no patients with $\mathrm{mHNPC}$. Other variables at the initial diagnosis of PC are also listed in Table 1.

\section{Functional outcomes}

Table 2 shows the functional outcomes evaluated by the Frankel grade before and after decompression surgery among men with mHNPC. Although two of eight patients (25.0\%) with mHNPC were ambulatory (Frankel grade D and E) preoperatively, six patients $(75.0 \%)$ were ambulatory postoperatively. Table 3 shows the functional outcomes evaluated by the Frankel grade before and after decompression surgery among men with mCRPC. Among 11 patients with mCRPC, only $3(27.3 \%)$ were ambulatory preoperatively while 6 (54.5\%) were ambulatory postoperatively.

\section{Oncological outcomes}

Figure 1a shows the Kaplan-Meier curve for OS after decompression surgery in the entire cohort, and Fig. $1 \mathrm{~b}$ shows the Kaplan-Meier curve among men with

Table 1 Patients' characteristics

\begin{tabular}{|c|c|c|}
\hline & Patients with mHNPC $(n=8)$ & Patients with mCRPC $(n=11)$ \\
\hline \multicolumn{3}{|l|}{ Variables at initial diagnosis of prostate cancer } \\
\hline Median prostate-specific antigen (range), ng/mL & $910(98-8900)$ & $232(6-4271)$ \\
\hline \multicolumn{3}{|l|}{ Biopsy Gleason scores, n (\%) } \\
\hline$\leq 7$ & $0(0.0 \%)$ & $2(18.2 \%)$ \\
\hline $8-10$ & $5(62.5 \%)$ & $9(81.8 \%)$ \\
\hline Unknown & $3(37.5 \%)$ & $0(0.0 \%)$ \\
\hline \multicolumn{3}{|l|}{ Extent of disease on bone scan } \\
\hline 0 & $0(0.0 \%)$ & $4(36.4 \%)$ \\
\hline 1 & $2(25.0 \%)$ & $2(18.2 \%)$ \\
\hline 2 & $1(12.5 \%)$ & $1(9.1 \%)$ \\
\hline 3 & $1(12.5 \%)$ & $1(9.1 \%)$ \\
\hline 4 & $0(0.0 \%)$ & $0(0.0 \%)$ \\
\hline Unknown & $4(50.0 \%)$ & $3(27.3 \%)$ \\
\hline \multicolumn{3}{|l|}{ Variables at decompression surgery } \\
\hline Median age (range), years & $72(62-78)$ & $65(46-71)$ \\
\hline Median prostate-specific antigen (range), ng/mL & $910(98-8900)$ & $67(0.1-307)$ \\
\hline \multicolumn{3}{|l|}{ Lesion of decompression surgery, n (\%) } \\
\hline Cervical spine & $0(0.0 \%)$ & $1(9.1 \%)$ \\
\hline Cervical-thoracic spine & $0(0.0 \%)$ & $2(18.2 \%)$ \\
\hline Thoracic spine & $6(75.0 \%)$ & $6(54.5 \%)$ \\
\hline Thoracic-lumbar spine & $0(0.0 \%)$ & $1(9.1 \%)$ \\
\hline Lumbar spine & $2(25.0 \%)$ & $1(9.1 \%)$ \\
\hline Median time to decompression surgery from symptoms occurrence (range), days & $4(0-8)$ & $2(0-14)$ \\
\hline The use of bone-targeted agents ${ }^{\mathrm{a}}, \mathrm{n}(\%)$ & $0(0.0 \%)$ & $4(36.3 \%)$ \\
\hline
\end{tabular}

mHNPC Metastatic hormone-naïve prostate cancer, $m C R P C$ Metastatic castration-resistant prostate cancer

${ }^{\mathrm{a}}$ Zoledronic acid or denosumab 
Table 2 Surgery for metastatic spinal cord compression from metastatic hormone-naïve prostate cancer: functional outcome

\begin{tabular}{lllllll}
\hline FRANKEL Grade & \multicolumn{3}{l}{ Postoperative } & & & Number of patients \\
\cline { 2 - 5 } Preoperative & A & B & C & D & E & Total (8) \\
\hline A & $1^{\mathrm{a}}$ & & & & 1 \\
B & & $1^{\mathrm{a}}$ & & & 1 \\
C & & & & $1^{\mathrm{b}}$ & $3^{\mathrm{b}}$ & 4 \\
D & & & & $2^{\mathrm{c}}$ & & 2 \\
E & & & & & 0 \\
\hline
\end{tabular}

${ }^{a}$ These patients were nonambulatory both before and after decompression surgery

${ }^{\mathrm{b}}$ These patients were nonambulatory before decompression surgery and ambulatory after surgery

'These patients were ambulatory both before and after decompression surgery

mHNPC and mCRPC. The median OS after decompression surgery in the entire cohort, men with mHNPC, and men with mCRPC was 17 months, not reached, and 8 months, respectively.

\section{Discussion}

MSCC from PC may cause irreversible neurological impairment, gait disturbance, and a poor quality of life. Thus, MSCC is an oncologic emergency that requires accurate diagnosis and rapid treatment [14]. When considering the treatment strategy for symptomatic MSCC, multidisciplinary approaches are needed [14].

The definitive treatments for MSCC are surgery and radiation therapy. Postoperative rehabilitation also has an important role [15]. Patchell et al. [10] demonstrated that decompression surgery plus postoperative conventional external beam radiation was superior to treatment with radiation alone for MSCC from various cancers in a phase III randomized clinical trial. However, their study had some bias; a significant proportion of ambulatory patients underwent surgery, and nonambulatory patients

Table 3 Surgery for metastatic spinal cord compression from metastatic castration-resistant prostate cancer: functional outcome

\begin{tabular}{|c|c|c|c|c|c|c|}
\hline \multirow{2}{*}{$\begin{array}{l}\text { FRANKEL Grade } \\
\text { Preoperative }\end{array}$} & \multicolumn{5}{|c|}{ Postoperative } & \multirow{2}{*}{$\begin{array}{l}\text { Number of patients } \\
\text { Total (11) }\end{array}$} \\
\hline & $\bar{A}$ & B & $\mathrm{C}$ & D & $\bar{E}$ & \\
\hline$A$ & & & & & & 0 \\
\hline B & & & & & & 0 \\
\hline C & & & $5^{\mathrm{a}}$ & $3^{b}$ & & 8 \\
\hline D & & & & $2^{c}$ & $1^{c}$ & 3 \\
\hline E & & & & & & 0 \\
\hline
\end{tabular}

${ }^{\text {a }}$ These patients were nonambulatory both before and after decompression surgery

${ }^{\mathrm{b}}$ These patients were nonambulatory before decompression surgery and ambulatory after surgery

'These patients were ambulatory both before and after decompression surgery were treated with radiotherapy [10]. Moreover, their study was published in 2005 [10]. PC treatment has been rapidly advancing; therefore, the efficacy of adding external beam radiation to decompression surgery should be re-evaluated in a prospective study.

The patient's prognosis, general health status, neurologic/mechanical function, and surgical morbidity and mortality should be considered when determining the treatment strategy for MSCC [9, 14, 16, 17]. Several tools for predicting survival of men undergoing surgical treatment of MSCC have been reported [18]. A PCspecific prognostic nomogram for mHNPC [3] or mCRPC [19] is also useful for prediction of survival and can provide significant information to orthopedic surgeons when considering the indication for surgery and determining the optimal surgical procedure.

The preoperative neurological and mechanical functions are also important factors when considering the treatment strategy for MSCC. Clarke et al. [9] reported that only one patient with preoperative Frankel grade B had a good functional outcome after surgery, although most patients with preoperative Frankel grade C, D, or E showed a favorable postoperative functional outcome. In our study, all patients with Frankel grade A and B underwent surgery and showed an unfavorable functional outcome postoperatively. Although selection bias cannot be ruled out, preoperative Frankel grade A or B could be carefully considered as an indication for surgery.

In the present study, although two of eight patients with mHNPC were ambulatory preoperatively, six of eight patients were ambulatory postoperatively and the median survival after surgery for MSCC was not reached. Crnalic et al. [20] also reported that 13 patients treated with surgery for MSCC from mHNPC achieved long survival and that 9 of 12 patients were ambulatory postoperatively despite the fact that only 1 of the $12 \mathrm{pa}-$ tients had been ambulatory preoperatively. Recovery of gait function may contribute to improvement in the quality of life, especially in patients with a good prognosis. Although clinical evidence is scarce, surgery for MSCC in men with mHNPC appears to be beneficial in appropriately selected patients in terms of achieving both a favorable quality of life and a good prognosis.

Patients who underwent surgical treatment of MSCC from mCRPC had a median survival time of only 8 months after surgery in the present study. Crnalic et al. [20] also reported that 41 patients who underwent surgical treatment of MSCC from mCRPC had a median survival time of only 5 months. The survival benefit obtained from surgery for MSCC in patients with mCRPC might be low; however, these patients might be surgical candidates for a good quality of life in highly selected situations $[9,20,21]$. 
A

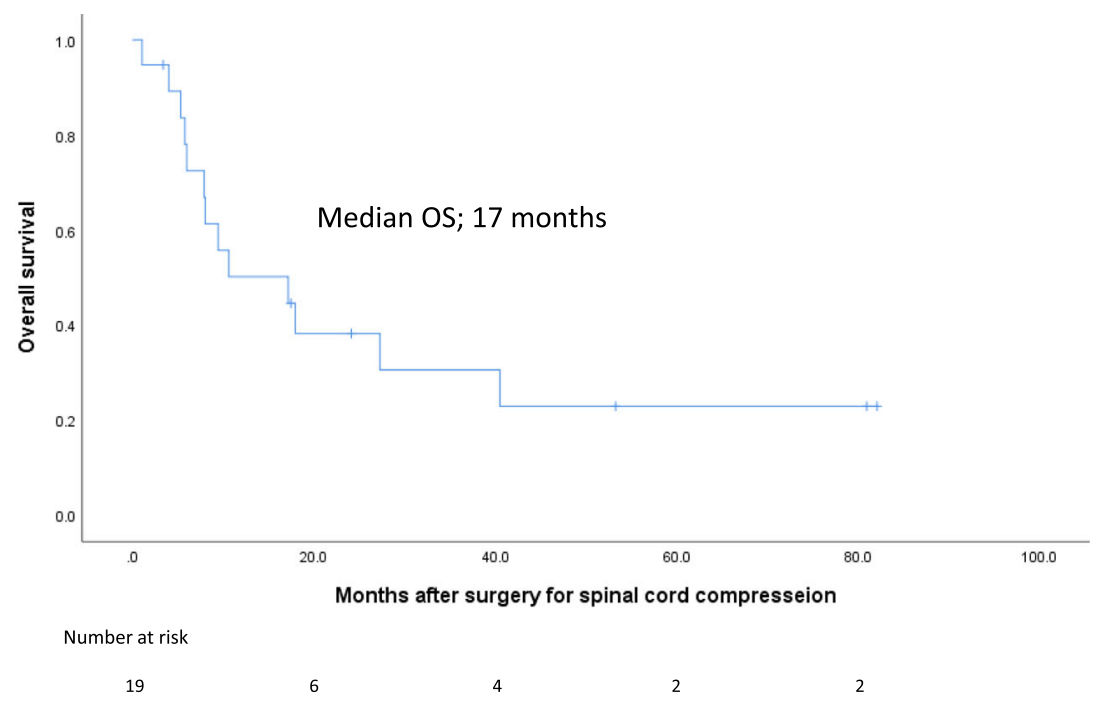

B

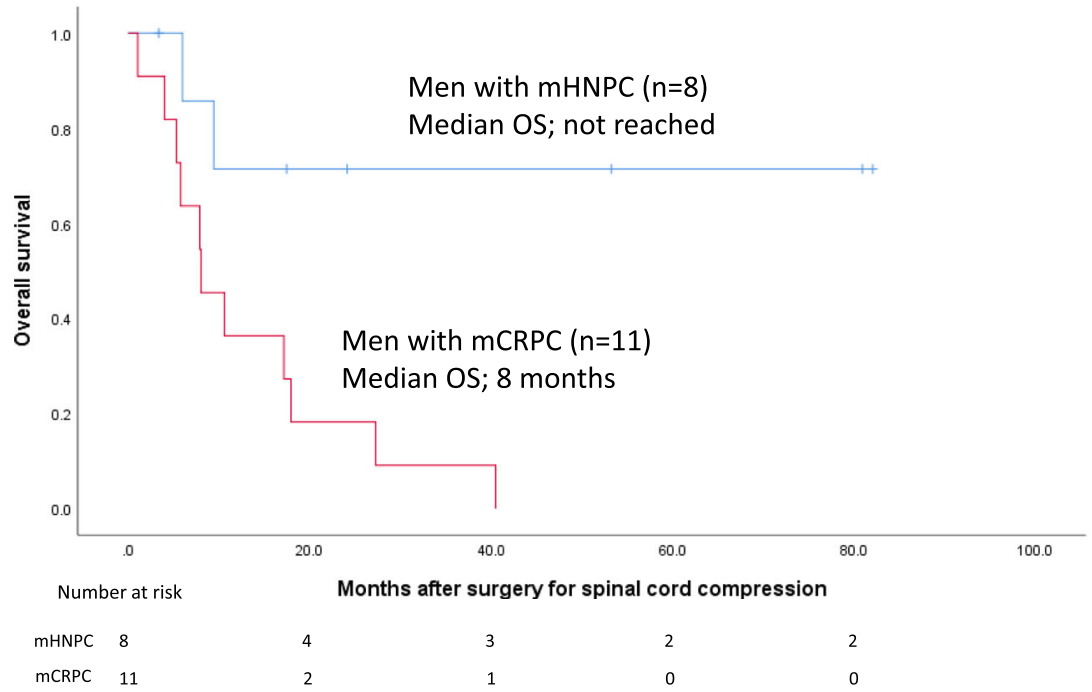

Fig. 1 Kaplan-Meier curves for overall survival (OS). a Kaplan-Meier curve for OS among men treated with decompression surgery for metastatic spinal cord compression originating from prostate cancer in the whole cohort $(n=19)$. The median OS was 17 months. $\mathbf{b}$ Kaplan-Meier curve for OS among men treated with decompression surgery for metastatic spinal cord compression originating from metastatic hormone-naïve prostate cancer ( $m H N P C, n=8)$ and metastatic castration-resistant prostate cancer ( $m C R P C, n=11)$. The median OS after surgery was not reached in men with $\mathrm{mHNPC}$ and 8 months in men with $\mathrm{mCRPC}$. The blue line indicates the survival of men with $\mathrm{mHNPC}$, and the red line indicates the survival of men with $\mathrm{MCRPC}$

Our study has several limitations, including its retrospective design and small cohort. However, we demonstrated that decompression and reconstruction surgery for symptomatic MSCC from PC might contribute to a favorable functional outcome among men with mHNPC and mCRPC. However, its role in improving the oncological outcome remains unclear. The treatment strategy should be determined by shared decision-making among patients, urologists, radiation oncologists, and orthopedic surgeons.

\section{Conclusions}

Our retrospective study has demonstrated that decompression and reconstruction surgery for symptomatic MSCC from PC might contribute to a favorable functional outcome among men with PC. Hormone-naïvety 
and mechanical/neurological function might be correlated with the postoperative outcome. The treatment strategy should be determined by shared decisionmaking among patients, urologists, radiation oncologists, and orthopedic surgeons.

\section{Abbreviations}

MSCC: Metastatic spinal cord compression; PC: Prostate cancer: mHNPC: Metastatic hormone-naive prostate cancer; mCRPC: Metastatic castration-resistant prostate cancer; OS: Overall survival

\section{Acknowledgments}

We thank Takuya Kawai, MD from the Department of Spine and Spinal Cord Surgery, Yokohama Brain and Spine Center for reviewing the manuscript from the viewpoint of orthopedic surgery.

\section{Authors' contributions}

Conceived and designed the study: TK, MY, HU, and YM. Analyzed the data: TK and YM. Wrote the paper: YM. All authors have read and approved the manuscript.

\section{Funding}

None.

\section{Availability of data and materials}

Because of ethical restrictions, the raw data underlying this paper are available upon request to the corresponding author.

\section{Ethics approval and consent to participate}

IRB approval of this study was obtained from Yokohama City University (D1603004). Informed consent was obtained in the form of opt-out on the web-site.

\section{Consent for publication}

We obtained IRB approval, including publication allowance.

\section{Competing interests}

The authors declare that they have no competing interests.

\section{Author details}

'Department of Urology and Renal Transplantation, Yokohama City University Medical Center, 4-57 Urafune-cho, Minami-ku, Yokohama, Kanagawa 2320024, Japan. ${ }^{2}$ Department of Urology, Yokohama City University School of Medicine, 3-9 Fukuura, Kanazawa-ku, Yokohama, Kanagawa 2360004, Japan.

Received: 29 August 2019 Accepted: 31 August 2020

Published online: 05 September 2020

\section{References}

1. Wong MC, Goggins WB, Wang HH, Fung FD, Leung C, Wong SY, Ng CF, Sung JJ. Global incidence and mortality for prostate Cancer: analysis of temporal patterns and trends in 36 countries. Eur Urol. 2016;70(5):862-74.

2. Schroder FH, Hugosson J, Roobol MJ, Tammela TL, Zappa M, Nelen V, Kwiatkowski M, Lujan M, Maattanen L, Lilja H, et al. Screening and prostate cancer mortality: results of the European randomised study of screening for prostate Cancer (ERSPC) at 13 years of follow-up. Lancet. 2014;384(9959): 2027-35.

3. Miyoshi Y, Noguchi K, Yanagisawa M, Taguri M, Morita S, Ikeda I, Fujinami K, Miura T, Kobayashi K, Uemura H. Nomogram for overall survival of Japanese patients with bone-metastatic prostate cancer. BMC Cancer. 2015;15:338.

4. Gandaglia G, Karakiewicz PI, Briganti A, Passoni NM, Schiffmann J, Trudeau V, Graefen M, Montorsi F, Sun M. Impact of the site of metastases on survival in patients with metastatic prostate Cancer. Eur Urol. 2015;68(2):325-34.

5. Scher HI, Halabi S, Tannock I, Morris M, Sternberg CN, Carducci MA, Eisenberger MA, Higano C, Bubley GJ, Dreicer R, et al. Design and end points of clinical trials for patients with progressive prostate cancer and castrate levels of testosterone: recommendations of the prostate Cancer clinical trials working group. J Clin Oncol. 2008;26(7):1148-59.
6. Williams BJ, Fox BD, Sciubba DM, Suki D, Tu SM, Kuban D, Gokaslan ZL, Rhines $L D$, Rao G. Surgical management of prostate cancer metastatic to the spine. J Neurosurg Spine. 2009;10(5):414-22.

7. Wu AS, Fourney DR. Evolution of treatment for metastatic spine disease. Neurosurg Clin N Am. 2004;15(4):401-11.

8. Byrne TN. Spinal cord compression from epidural metastases. N Engl J Med. 1992;327(9):614-9.

9. Clarke MJ, Molina CA, Fourney DR, Fisher CG, Gokaslan ZL, Schmidt MH, Rhines LD, Fehlings MG, Laufer I, Patel SR, et al. Systematic review of the outcomes of surgical treatment of prostate metastases to the spine. Global Spine J. 2017;7(5):460-8.

10. Patchell RA, Tibbs PA, Regine WF, Payne R, Saris S, Kryscio RJ, Mohiuddin M, Young B. Direct decompressive surgical resection in the treatment of spinal cord compression caused by metastatic cancer: a randomised trial. Lancet. 2005;366(9486):643-8

11. Epstein Jl, Egevad L, Amin MB, Delahunt B, Srigley JR, Humphrey PA, Grading C. The 2014 International Society of Urological Pathology (ISUP) consensus conference on Gleason Grading of prostatic carcinoma: definition of Grading patterns and proposal for a new Grading system. Am J Surg Pathol. 2016;40(2):244-52.

12. Soloway MS, Hardeman SW, Hickey D, Raymond J, Todd B, Soloway S, Moinuddin M. Stratification of patients with metastatic prostate cancer based on extent of disease on initial bone scan. Cancer. 1988;61(1):195-202.

13. Frankel HL, Hancock DO, Hyslop G, Melzak J, Michaelis LS, Ungar GH, Vernon JDS, Walsh JJ. The value of postural reduction in the initial management of closed injuries of the spine with paraplegia and tetraplegia. Paraplegia. 1969;7:179.

14. Lawton AJ, Lee KA, Cheville AL, Ferrone ML, Rades D, Balboni TA, Abrahm $J$ L. Assessment and Management of Patients with Metastatic Spinal Cord Compression: a multidisciplinary review. J Clin Oncol. 2019;37(1):61-71.

15. Eriks IE, Angenot EL, Lankhorst GJ. Epidural metastatic spinal cord compression: functional outcome and survival after inpatient rehabilitation. Spinal Cord. 2004;42(4):235-9.

16. Cheng KH, Mariampillai A, Lee KK, Vuong B, Luk TW, Ramjist J, Curtis A, Jakubovic $\mathrm{H}$, Kertes $\mathrm{P}$, Letarte $\mathrm{M}$, et al. Histogram flow mapping with optical coherence tomography for in vivo skin angiography of hereditary hemorrhagic telangiectasia. J Biomed Opt. 2014;19(8):086015.

17. Yamashita T, Aota Y, Kushida K, Murayama H, Hiruma T, Takeyama M, Iwamura Y, Saito T. Changes in physical function after palliative surgery for metastatic spinal tumor: association of the revised Tokuhashi score with neurologic recovery. Spine (Phila Pa 1976). 2008;33(21):2341-6.

18. Tokuhashi Y, Matsuzaki H, Oda H, Oshima M, Ryu J. A revised scoring system for preoperative evaluation of metastatic spine tumor prognosis. Spine (Phila Pa 1976). 2005;30(19):2186-91.

19. Yang YJ, Lin GW, Li GX, Dai B, Ye DW, Wu JL, Xie HY, Zhu Y. External validation and newly development of a nomogram to predict overall survival of abiraterone-treated, castration-resistant patients with metastatic prostate cancer. Asian J Androl. 2018;20(2):184-8.

20. Crnalic S, Hildingsson C, Wikstrom P, Bergh A, Lofvenberg R, Widmark A. Outcome after surgery for metastatic spinal cord compression in 54 patients with prostate cancer. Acta Orthop. 2012;83(1):80-6.

21. Ju DG, Zadnik PL, Groves ML, Hwang L, Kaloostian PE, Wolinksy JP, Witham TF, Bydon A, Gokaslan ZL, Sciubba DM. Factors associated with improved outcomes following decompressive surgery for prostate cancer metastatic to the spine. Neurosurgery. 2013;73(4):657-66 discussion 666.

\section{Publisher's Note}

Springer Nature remains neutral with regard to jurisdictional claims in published maps and institutional affiliations. 